\title{
Opioid-Induced Cardioprotection against Ischemia-Reperfusion Injury: The Challenge in Diabetes
}

\author{
Shaoqing Lei ${ }^{1,2,3}$, Wating Su ${ }^{1}$, Rui Xue ${ }^{1}$, Huimin Liu ${ }^{1}$, Liangqing Zhang ${ }^{2}$, Huilai Miao ${ }^{2}$, Youtan Liu ${ }^{2}$, Haobo Li $^{3}$, Michael G Irwin ${ }^{3}$ and Zhengyuan Xia ${ }^{2,3 *}$ \\ ${ }^{1}$ Department of Anaesthesiology, Renmin Hospital of Wuhan University, Wuhan, China \\ ${ }^{2}$ Department of Anesthesiology, Affiliated Hospital of Guangdong Medical College, Zhanjiang, Guangdong, China \\ 3Department of Anaesthesiology, the University of Hong kong, Hongkong SAR, China
}

*Corresponding author: Dr. Zhengyuan Xia, Department of Anaesthesiology, the University of Hong Kong, Hong Kong, Tel: 852-3917-9794; 852-3917-9786; Email: zyxia@hku.hk

Rec date: Oct 01, 2015; Acc date: Oct 13, 2015; Pub date: Oct 16, 2015

Copyright: @ 2015 Lei S, et al. This is an open-access article distributed under the terms of the Creative Commons Attribution License, which permits unrestricted use, distribution, and reproduction in any medium, provided the original author and source are credited.

\begin{abstract}
Ischemic heart disease is the leading cause of morbidity and mortality in diabetes. Patients with diabetes are particularly at risk of perioperative myocardial infarction, and are less resistant to myocardial ischemia-reperfusion injury (IRI), but the underlying mechanisms are very unclear. Opioid conditioning has been well demonstrated to be protective against myocardial IRI like ischemic conditioning, but this effect is compromised in diabetic condition, and little is known about the role of opioid-induced cardioprotection during diabetes. This brief review is to provide a summary of our present understanding of the effects of diabetes on opioids induced protection against myocardial IRI and the challenges of limiting IRI by opioids in the diabetic heart.
\end{abstract}

\section{Keywords: Opioid; Ischemia-reperfusion injury; Ischemic Subtypes of Opioid Receptors}

conditioning; Diabetes

\section{Introduction}

Cardiovascular disease, especially ischemic heart disease (IHD), is a major complication in patients with diabetes and remains the leading cause of death globally [1-3]. The standard clinical therapy for ischemic heart disease is timely re-establishment of blood supply (i.e., reperfusion) in order to rescue the ischemic tissue. Paradoxically, however, restoration of blood flow may cause additional cell death in cardiomyocytes rather than initiate salvage the ischemic tissue, a phenomenon termed "ischemia-reperfusion injury (IRI)"[4-6]. In 1986, Murry et al. firstly observed that myocardial IRI could be reduced by ischemic preconditioning, which was achieved by brief episodes of ischemia and reperfusion, given before prolonged ischemia [7]. However, its clinical application has been limited because of the unpredictable occurrence of ischemia in patients. In 2003, Zhao et al. applied transient brief interruptions of reperfusion to ischemic episodes and resulted in reduced myocardial injury, termed "ischemic postconditioning" [8]. Subsequent studies expanded this beneficial myocardial conditioning to remote conditioning and pharmacological conditioning $[9,10]$. It is of note that myocardial conditioning such as preconditioning mediated cardioprotection could be blocked by opioid receptor antagonists [11] and mimicked by opioid receptor agonists, indicating the involvement of activation of opioid receptor signaling pathways in myocardial IRI protection . Unfortunately, this opioidinduced cardioprotection is abolished or compromised under pathological conditions such as diabetes $[12,13]$. This review intends to help understand the role of opioid-induced cardioprotection against IRI and the challenges of limiting myocardial IRI in the diabetic hearts.
An "opioid" is any narcotic not only derived from opium, suggesting endogenous substances such as enkephalins or endorphins that can effect on the brain to decrease the sensation of pain are also classified as opioids. Endogenous and exogenous opioid agonists exert their pharmacological and physiological effects through binding to specific opioid receptors. Opioid receptors (ORs) are classified into four major types, including the mu $(\mu)$, delta $(\delta)$, kappa $(\kappa)$ and OR-like subtype 1 receptor (ORL-1). The structures and functions of these four opioid receptor subtypes are well described by other reviews [14-16]. ORs are G-protein-coupled receptors [17]. After opioid agonist activates the ORs, G-protein signaling leads to a series of changes in intracellular signaling transduction, and subsequently affects cell function. The effects of $\mu, \delta$, and $\kappa$-receptor could be well inhibited by the nonselective opioid antagonist naloxone [14], a drug widely used in clinic. ORs are mainly expressed in the brain and spinal cord [14]. Interestingly, studies also found that $\delta$ and $\kappa$ but not $\mu$ receptor and ORL- 1 are expressed in cardiac tissues $[14,18,19]$. This suggests that $\delta$ and $\kappa$-receptor may play an important role in mediating opioidinduced cardioprotection. Furthermore, cardiac issues are capable of synthesizing, storing, and releasing of opioid receptor peptides [20], such as endorphin, dynorphin, and encephalin, which have high affinity for $\mu$-, $\kappa$ - and $\delta$-opioid receptors, respectively, indicating that these endogenous opioid peptides may contribute to ischemic tolerance in heart.

\section{Role of opioid receptor in opioid-induced cardioprotection}

It is not surprising, given the presence of $\delta$ and $\kappa$-OR expressed in the heart, that both the selective agonist of $\delta$ and $\delta$-OR can reduce myocardial infract size in many species $[21,22]$. The roles of $\delta$-OR in ischemic preconditioning are well documented by the review by Dragasis $S$ et al. [14]. Several studies also found that cardioprotection mediated by postconditioning involved the activation of $\delta$-OR $[23,24]$ 
and the preservation of myocardial opioid content [24]. The use of $\delta$ OR antagonist naltrindole abolished methadone and morphine induced reduction in myocardial infarct size during reperfusion [25]. Compared with the clear evidence of $\delta$-OR in reducing myocardial IRI, the role of $\kappa-\mathrm{OR}$ in cardioprotection is more controversial. However, a recent study reported that administration of nor-binaltorphimin to block $\kappa-\mathrm{OR}$ eliminated fentanyl postconditioning mediated cardioprotection and the enhancement of cardioprotection mediated by combined fentanyl and limb remote ischemic postconditioning [26]. Another independent study showed that remote ischemic postconditioning requires the activation of both $\delta$ and $\kappa$-OR [27]. Interestingly, the clinically used opioid drugs, such as remifentanil, which has high degree of $\mu$-OR selectivity with a lower affinity with $\delta$ $\mathrm{OR}$ and $\kappa-\mathrm{OR}$, have been reported to be beneficial to reduce myocardial IRI [28]. However, Remifentanil post-conditioning protects the heart from IRI involved both $\delta$-OR and $\kappa$-OR but not $\mu$-OR activation [29]. All these results suggest that the stimulation of $\delta$-OR and $\kappa-O R$ with selective or non-selective agonists may play an important role in the cardioprotective effects of cardiac conditioning.

\section{The challenge of opioid-induced cardioprotection in diabetes}

Although the evidences of ORs ( $\delta$ and $\kappa-\mathrm{OR})$ and opioid-induced cardioprotection are clearly described above in non-diabetic condition, the effects of opioids induced cardioprotection under diabetic condition are compromised. It was reported that remifentanil effectively reduced myocardial infarction in normal rats, no matter it was used as preconditioning or as postconditioning stimuli or used as continuous infusion during ischemia and reperfusion [30]. However, in diabetic condition, the cardiac protection of remifentanil preconditioning against IRI was mitigated, which might be associated with reduced recovery of the activities of proteins involved in antiapoptotic pathways including ERK1/2 [13]. Sufentanil is widely used in clinical anaesthesia because of its protective effects against myocardial IRI, but it was ineffective in preventing against IRI in diabetic rats, which is associated with the activation of GSK-3 $\beta$ [12]. Further, the selective $\kappa$-OR agonist significantly reduced the myocardial infarct size and increased the expression of stress-inducible heat-shock protein 70 in normal rats, but its effects were abolished in streptozotocin-induced diabetic rats which might be restored by insulin replacement [31]. However, the underlying mechanisms in which diabetes abolish opioid-induced cardioprotection are not certain.

\section{Molecular perspectives of opioid-induced cardioprotection in diabetes}

Cardioprotection by opioid conditioning and ischemic conditioning (in particular, preconditioning) appear to share common elements in cellular mechanisms [11]. Cardioprotection by preconditioning is mostly initiated through stimulation of G-protein coupled receptors by ligands, including bradykinin, opioids, acetylcholine and tumor necrosis factor (TNF)-alpha [32,33]. Then ligand-receptor binding activates multiple signaling cascades, especially protein kinase $\mathrm{C}$ (in particular, $\mathrm{PKC} \varepsilon$ ), reperfusion injury salvage kinase (RISK), including PI3 kinase/Akt, extracellular signal regulated kinase (ERK), p70S6 kinase and glycogen synthase kinase $3 \beta$ (GSK-3 $\beta$ ), or survival activating factor enhancement (SAFE) pathways, including janus activated kinase (JAK) and signal transducer and activator of transcription (STAT) [34-36] (Figure 1). It is well demonstrated opioidinduced cardioprotection in normal rodents involves several similar signaling, such as protein kinase C (PKC) [37], GSK-3 $\beta$ [38], ERK [39],
JAK/STAT [40], and so on. However, diabetes has been shown to be associated with impaired PI3 kinase/Akt signaling (components of both insulin signaling and the RISK pathway), essentially all kinases proposed to contribute to the infarct-sparing effect of ischemic conditioning. For example, impaired phosphorylation of PKC, PI3 kinase/Akt, ERK, STAT3, and GSK-3 $\beta$ have been demonstrated in diabetic hearts as reviewed by Wider J and Przyklenk K [2]. These are potential mechanisms that rendered the diabetic hearts are more susceptible to IRI and less sensitive to opioid conditioning (Figure 1). However, further research should be directed at elucidating the role of OR-induced cardioprotection in diabetic condition and developing rational drug to reduce myocardial IRI and restore opioids induced cardioprotection in diabetes. A most recent study [41] has showed that selective activation of $\kappa$-opioid receptor reduced hyperglycemia in streptozotocin-induced diabetic mice that might be relevant to increased adiponectin, a molecule with anti-ischemic and anti-diabetic property whose secretion is reduced in diabetes, which shed light on exploring the mechanism and effectiveness of opioid cardioprotection in diabetes.

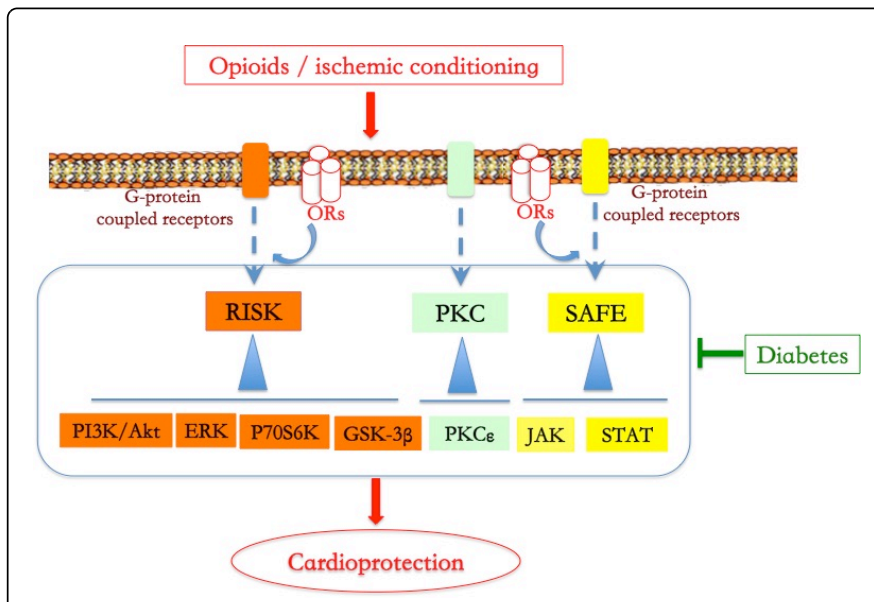

Figure 1: Schematic of proposed mechanism of opioid conditioning or ischemic conditioning induced cardioprotection. Opioids conditioning or ischemic conditioning protects the heart against ischemia-reperfusion injury, which initiates through stimulation of G-protein coupled receptors by ligands, then activates multiple signaling cascades, especially protein kinase C (PKC), survivor activating factor enhancement (SAFE) and reperfusion injury salvage kinase (RISK) pathways, and ultimately attenuates ischemia-reperfusion injury, but these effects are abolished or compromised under diabetic condition.

\section{Conclusion}

Opioid conditioning mimics ischemic conditioning induced protection against myocardial IRI in normal condition. This effect is produced by the activation of ORs, especially $\delta$-OR and $\kappa-O R$. However, the opioid-induced cardioprotection is abolished or compromised in diabetic conditions. Gaining more insight into the mechanism(s) by which diabetes affects opioid-induced cardioprotection may assist in developing new therapeutic strategies to improve cardiac function and to restore effectiveness of opioids conditioning in cardiac operations in the setting of diabetes, including patients with genetic predisposition to type 2 diabetes [42] whose glucose levels might only be slightly increase but yet may 
accelerate the development of atherosclerosis and increase the risk of coronary heart disease.

\section{Acknowledgment}

The study was supported by the grant from the National Natural Science Foundation of China (NSFC 813000674, and 81270899).

\section{References}

1. Gilbert RE, Krum H (2015) Heart failure in diabetes: effects of antihyperglycaemic drug therapy. Lancet 385: 2107-2117.

2. Wider J, Przyklenk K (2014) Ischemic conditioning: the challenge of protecting the diabetic heart. Cardiovasc Diagn Ther 4: 383-396.

3. Kim T, He L, Johnson MS, Li Y, Zeng L, et al. (2014) Carnitine Palmitoyltransferase 1b Deficiency Protects Mice from Diet-Induced Insulin Resistance. J Diabetes Metab 5: 361.

4. Ashraf M, Zhai X (1995) Pathophysiology of myocardial reperfusion injury: role of oxygen free radicals. Transplant Proc 27: 2800-2801.

5. Basso C, Thiene G (2006) The pathophysiology of myocardial reperfusion: a pathologist's perspective. Heart 92: 1559-1562.

6. Fox KA, Bergmann SR, Sobel BE (1985) Pathophysiology of myocardial reperfusion. Annu Rev Med 36: 125-144.

7. Murry CE, Jennings RB, Reimer KA (1986) Preconditioning with ischemia: a delay of lethal cell injury in ischemic myocardium. Circulation 74: 1124-1136.

8. Zhao ZQ, Corvera JS, Halkos ME, Kerendi F, Wang NP, et al. (2003) Inhibition of myocardial injury by ischemic postconditioning during reperfusion: comparison with ischemic preconditioning. Am J Physiol Heart Circ Physiol 285: H579-588.

9. Sivaraman V, Pickard JM1, Hausenloy DJ1 (2015) Remote ischaemic conditioning: cardiac protection from afar. Anaesthesia 70: 732-748.

10. Sivaraman V, Yellon DM (2014) Pharmacologic therapy that simulates conditioning for cardiac ischemic/reperfusion injury. J Cardiovasc Pharmacol Ther 19: 83-96.

11. Schultz JE, Rose E, Yao Z, Gross GJ (1995) Evidence for involvement of opioid receptors in ischemic preconditioning in rat hearts. Am J Physiol 268: H2157-2161.

12. Chen QL, Gu EW, Zhang L, Cao YY, Zhu Y, et al. (2013) Diabetes mellitus abrogates the cardioprotection of sufentanil against ischaemia/ reperfusion injury by altering glycogen synthase kinase-3beta. Acta Anaesthesiol Scand 57: 236-42.

13. Kim HS, Cho JE, Hwang KC, Shim YH, Lee JH, et al. (2010) Diabetes mellitus mitigates cardioprotective effects of remifentanil preconditioning in ischemia-reperfused rat heart in association with anti-apoptotic pathways of survival. Eur J Pharmacol 628: 132-9.

14. Dragasis S, Bassiakou E, Iacovidou N, Papadimitriou L, Andreas Steen P, et al. (2013) The role of opioid receptor agonists in ischemic preconditioning. Eur J Pharmacol 720: 401-408.

15. Tanaka K, Kersten JR, Riess ML (2014) Opioid-induced cardioprotection. Curr Pharm Des 20: 5696-5705.

16. Minami M, Satoh M (1995) Molecular biology of the opioid receptors: structures, functions and distributions. Neurosci Res 23: 121-145.

17. Corbett AD, Henderson G, McKnight AT, Paterson SJ (2006) 75 years of opioid research: the exciting but vain quest for the Holy Grail. Br J Pharmacol 147 Suppl 1: S153-162.

18. Ventura C, Bastagli L, Bernardi P, Caldarera CM, Guarnieri C (1989) Opioid receptors in rat cardiac sarcolemma: effect of phenylephrine and isoproterenol. Biochim Biophys Acta 987: 69-74.

19. Ventura C, Spurgeon H, Lakatta EG, Guarnieri C, Capogrossi MC (1992) Kappa and delta opioid receptor stimulation affects cardiac myocyte function and $\mathrm{Ca} 2+$ release from an intracellular pool in myocytes and neurons. Circ Res 70: 66-81.
20. Barron BA, Jones CE, Caffrey JL (1995) Pericardial repair depresses canine cardiac catecholamines and met-enkephalin. Regul Pept 59: 313-320.

21. Gross ER, Hsu AK, Gross GJ (2004) Opioid-induced cardioprotection occurs via glycogen synthase kinase beta inhibition during reperfusion in intact rat hearts. Circ Res 94: 960-966.

22. Peart JN, Gross ER, Reichelt ME, Hsu A, Headrick JP, et al. (2008) Activation of kappa-opioid receptors at reperfusion affords cardioprotection in both rat and mouse hearts. Basic Res Cardiol 103: 454-463.

23. Jang Y, Xi J, Wang H, Mueller RA, Norfleet EA, et al. (2008) Postconditioning prevents reperfusion injury by activating delta-opioid receptors. Anesthesiology 108: 243-250.

24. Zatta AJ, Kin H, Yoshishige D, Jiang R, Wang N, et al. (2008) Evidence that cardioprotection by postconditioning involves preservation of myocardial opioid content and selective opioid receptor activation. Am J Physiol Heart Circ Physiol 294: H1444-51.

25. Gross ER, Hsu AK, Gross GJ (2009) Acute methadone treatment reduces myocardial infarct size via the delta-opioid receptor in rats during reperfusion. Anesth Analg 109: 1395-1402.

26. Xu YC, Li RP, Xue FS, Cui XL, Wang SY, et al. (2015) Î I$^{\circ}$-Opioid receptors are involved in enhanced cardioprotection by combined fentanyl and limb remote ischemic postconditioning. J Anesth 29: 535-543.

27. Surendra H, Diaz RJ, Harvey K, Tropak M, Callahan J, et al. (2013) Interaction of $\hat{\mathrm{I}}^{\prime}$ and $\hat{\mathrm{I}}^{\circ}$ opioid receptors with adenosine $\mathrm{A} 1$ receptors mediates cardioprotection by remote ischemic preconditioning. J Mol Cell Cardiol 60: 142-150.

28. Wong GT, Huang Z, Ji S, Irwin MG (2010) Remifentanil reduces the release of biochemical markers of myocardial damage after coronary artery bypass surgery: a randomized trial. J Cardiothorac Vasc Anesth 24: 790-796.

29. Wong GT, Li R, Jiang LL, Irwin MG (2010) Remifentanil postconditioning attenuates cardiac ischemia-reperfusion injury via kappa or delta opioid receptor activation. Acta Anaesthesiol Scand 54: 510-518.

30. Chun KJ, Park YH, Kim JS, Jang Y, Kim JH, et al. (2011) Comparison of 5 different remifentanil strategies against myocardial ischemia-reperfusion injury. J Cardiothorac Vasc Anesth 25: 926-30.

31. Qi JS, Kam KW, Chen M, Wu S, Wong TM (2004) Failure to confer cardioprotection and to increase the expression of heat-shock protein 70 by preconditioning with a kappa-opioid receptor agonist during ischaemia and reperfusion in streptozotocin-induced diabetic rats. Diabetologia 47: 214-20.

32. Cohen MV, Yang XM, Liu GS, Heusch G, Downey JM (2001) Acetylcholine, bradykinin, opioids, and phenylephrine, but not adenosine, trigger preconditioning by generating free radicals and opening mitochondrial K(ATP) channels. Circ Res 89: 273-278.

33. Lecour S, Smith RM, Woodward B, Opie LH, Rochette L, et al. (2002) Identification of a novel role for sphingolipid signaling in TNF alpha and ischemic preconditioning mediated cardioprotection. J Mol Cell Cardiol 34: 509-18.

34. Heusch G, Boengler K, Schulz R (2008) Cardioprotection: nitric oxide, protein kinases, and mitochondria. Circulation 118: 1915-1919.

35. Lecour S (2009) Activation of the protective Survivor Activating Factor Enhancement (SAFE) pathway against reperfusion injury: Does it go beyond the RISK pathway? J Mol Cell Cardiol 47: 32-40.

36. Goodman MD, Koch SE, Fuller-Bicer GA, Butler KL (2008) Regulating RISK: a role for JAK-STAT signaling in postconditioning? Am J Physiol Heart Circ Physiol 295: H1649-1656.

37. Zhang Y, Chen ZW, Girwin M, Wong TM (2005) Remifentanil mimics cardioprotective effect of ischemic preconditioning via protein kinase $\mathrm{C}$ activation in open chest of rats. Acta Pharmacol Sin 26: 546-550.

38. Wu QL, Shen T, Ma H, Wang JK (2012) Sufentanil postconditioning protects the myocardium from ischemia-reperfusion via PI3K/AktGSK-3 $\hat{I}^{2}$ pathway. J Surg Res 178: 563-570. 
Citation: Lei S, Su W, Xue R, Liu H, Zhang L, et al. (2015) Opioid-Induced Cardioprotection against Ischemia-Reperfusion Injury: The Challenge in Diabetes. J Diabetes Metab 6: 616. doi:10.4172/2155-6156.1000616

Page 4 of 4

39. Ikeda Y, Miura T, Sakamoto J, Miki T, Tanno M, et al. (2006) Activation of ERK and suppression of calcineurin are interacting mechanisms of cardioprotection afforded by delta-opioid receptor activation. Basic Res Cardiol 101: 418-426.

40. Gross ER, Hsu AK, Gross GJ (2006) The JAK/STAT pathway is essential for opioid-induced cardioprotection: JAK2 as a mediator of STAT3, Akt, and GSK-3 beta. Am J Physiol Heart Circ Physiol 291: H827-834.
41. Shang Y, Guo F, Li J, Fan R, Ma X, et al. (2015) Activation of $\hat{\mathrm{I}}^{\circ}$-opioid receptor exerts the glucose-homeostatic effect in streptozotocin-induced diabetic mice. J Cell Biochem 116: 252-259.

42. Pannacciulli N, De Pergola G, Ciccone M, Rizzon P, Giorgino F, et al (2003) Effect of family history of type 2 diabetes on the intima-media thickness of the common carotid artery in normal-weight, overweight, and obese glucose-tolerant young adults. Diabetes Care 26: 1230-4. 